\title{
Effects of Educational Intervention among Reproductive Age Group Women on Safe Abortion
}

\author{
Kalpana Silwal, ${ }^{1}$ Tumla Shrestha, ${ }^{1}$ Ram Krishna Dulal ${ }^{2}$ \\ 'Lalitpur Nursing Campus, Lalitpur, Nepal, ${ }^{2}$ National Open College, Lalitpur, Nepal.
}

Introduction: Many reproductive aged women needlessly die due to unsafe abortion even when they seek help to terminate their unwanted pregnancy. These deaths could have been prevented had they been aware that safe abortion service was available to them. The study aimed at finding out the effectiveness of the education intervention in improving knowledge among reproductive age group women regarding the safe abortion.

Methods: An experimental intervention was carried out on safe abortion education among the reproductive age group women. The impact of pre- and post- intervention was evaluated by using a set of structured questionnaire in local language. The obtained data was analyzed by using the Excel and Statistical Package for the Social Sciences, version 12.0 for windows and result was interpreted.

Results: The post intervention finding revealed a significantly higher $(p=0.001)$ mean on knowledge among participants about safe abortion compared to pre-observational test. The mean difference between the pre-test and post-test was $64.1 \%$ (Pre-test $11.18 \pm 12.88$ Post-test $75.28 \pm 9.56$ ). The research hypothesis was accepted with $p$ value paired t-test at $<0.001(0.05)$. The result supports that the educational intervention was effective in increasing safe abortion awareness among reproductive aged group women.

Conclusion: The safe abortion educational intervention program was instrumental to improve reproductive age women's knowledge considerably about safe abortion service.

Keywords: educational intervention; knowledge; safe abortion; women.

\section{INTRODUCTION}

Nepal has a population of 26.9 million and women comprise nearly half $(49.8 \%)$ of the total population. Among the female population, almost half (49\%) of them are in the reproductive age group (15 to 49 years). Induced abortion and unwanted pregnancy occur in Nepal just as in every society and inevitably it has become a major problem with health issues for women as in other parts of world.
Nepal Demographic and Health Survey 2011 indicated that urban-rural differentials fertility rate in Nepal are obvious with rural women ( 2.8 births) having an average of over one child more than urban women (1.6 births). Women are disadvantaged in terms of educational

Correspondence: Kalpana Silwal, Lalitpur Nursing Campus, Sanepa, Lalitpur, P.O. Box -1885, Nepal. Email: kalpanasilwal@gmail. com, Phone: +977-9841-516491. 
attainment. This is observed at all levels of education, with the female-male difference especially obvious among those with no education and those with School Leaving Certificate (SLC) or higher levels of education. ${ }^{2}$ This indicates the importance of the issue in the rural is definitely higher than in the urban.

An official report published by the government of Nepal indicated that among 7,000 pregnant women in Nepal, a total of 2,000 cases experienced unplanned pregnancy and among which a total of 1,000 carried out an abortion. In Nepal, the rate of unplanned pregnancy is $35 \% .^{3}$

Abortion is legalized in Nepal since 2003, and conditional abortions are performed both in public and private hospitals and clinics. The trend of abortion care in Nepal shows an increase in abortion cases in the private sector. It is reported that there were 89 service centres in the public sector and 78 in the private sector in 2006/07. Fifty-three percent of all service centres belong to the public sector that delivered only 12 percent of the total services whereas the private sector has 47 percent of all centres, but delivered 88 percent of all services. By June 2008, a total of 229,583 comprehensive abortion care was provided but no disaggregated information on public and private deliveries is available due to the single reporting system. ${ }^{4}$

Despite abortion is legalized most of the women are still unaware about the current legal provision of safe abortion service being facilitated by the government. Consequently, individual woman desiring termination of their unwanted pregnancy happened to accept even an unsafe abortions service spontaneously or as intimidated by their friends or family members or even a broker. The implications of the findings from studies of health and illness behaviour suggest that we need to rethink aspects of healthcare delivery, health education and health promotion and the role of not-for profit organisations and communities.

In order to reduce in buying of such an unsafe service by ignorant women silently, it is utmost important to put a system in place within the Nepalese health system without a delay.

This study was designed to provide valuable and profound insights into the issue of unsafe abortion with the objective of identifying whether unsafe abortion was due to unmet need of education and awareness among the women of reproductive age, particularly those living at Fulbari Village Development Committee, ward no. 6 and 7 of Chitwon district in Nepal. The findings of this study can certainly provide a useful reference for future health education programme in Nepal.

\section{METHODS}

The design of this study was experimental, aiming at evaluating the impact or efficacy of educational intervention, where a pre- test prior to intervention and a post test after the intervention were carried out.

A total of 68 women living at Fulbari Village Development Committee (VDC), ward no. 6 and 7 of Chitwon district in Nepal were selected through a systematic random sampling between $15^{\text {th }}$ July to $23^{\text {rd }}$ August 2012. A written permission to conduct the study was obtained from the local authorities of the selected VDC. Informed consent was obtained from the each subject prior to interview.

An adequate number of questions were developed to meet content validity being based on the relevant literature and local women's demographic scenario including their education. To ensure the content validity of the instrument (questionnaire), it was then submitted to two academicians working in the areas of midwifery research and teaching who hold expert knowledge and experience about medical abortion.

After obtaining approval, the questions were translated in to Nepali language before the application. Subsequently, field pretesting was done in $10 \%$ of the total sample size at Gopalgunj village in Fulbari VDC. Based on response, a small modification was made.

After pre- testing in a total of 68 respondents about their knowledge on abortion, one and half hour interventional teaching session was conducted using educational materials (brochures, pamphlets and training materials). The educational intervention was carried out in three different sessions as per convenience of the subjects of the study and each group containing a proportional number.

After 2 weeks of educational intervention, a post - test was undertaken by using the same set of questionnaire that was used in the pre- test. Only a total number of 60 participants responded the structured interview. A total of 8 cases remained absent due to women's festival called Teej. The obtained data was entered in to the Excel and was analyzed by using Statistical Package for the Social Sciences, version 12.0 for windows and result was interpreted.

\section{RESULTS}

The respondents' age ranged from 20 to 35 years. Among them, 26 respondents $(43.3 \%)$ belonged to the 31-35 years of age group. The mean age with 
standard deviation was $28.82 \pm 4.97$ years. A total of 53 respondents $(88.3 \%)$ belong to the Hindu religion whereas 33 respondents $(55 \%)$ belonged to Chhetri ethnic group followed by Brahmin. Other ethnic groups constituted $12(20 \%)$ of the respondents. Regarding family, 39 respondents $(65 \%)$ belonged to nuclear families. Among the respondents, 39 (65\%) had under SLC level of education and only 18 (30\%) had passed their SLC. Of those respondents, only 3 (5\%) were illiterate. The occupation for 47 (78.3\%) respondents' was a combined occupation of housewife and agricultural work and just 2 respondents (3.3\%) were engaged in business.

Only $3(5 \%)$ of the respondents in the pre-test answered correctly the meaning of abortion as termination of pregnancy before the foetus is viable, i.e. before 4-5 months, whereas 56 (93.3\%) responded correctly answered to the same question in the post-test. The respondents' awareness regarding the meaning of unsafe abortion reveals that the correct responses ranged from 1 to $11(1.6 \%$ to $18.3 \%)$ in the pre-test and 27 to 57 (45\% to $95 \%)$ in the post-test. Regarding their awareness of the meaning of safe abortion, the results in the pre-test for awareness ranged from 5 to $10(8.3 \%$ to $16.6 \%)$ and in the post-test their results ranged from 34 to $53(56.7 \%$ to $88.3 \%)$.

Three to twenty-one ( $5 \%$ to $35 \%$ ) of the respondents correctly answered the individual reasons for seeking abortion. The area where 21 (35\%) of the respondents scored highest was in their belief that the completion (adequacy) of number of kids in the family was the main condition for seeking abortion. From the post-test results it can be seen that 44 to $59(73.3 \%$ to $98.3 \%)$ of the respondents had increased their awareness of reasons for seeking an abortion. Regarding the knowledge on factors leading to unsafe abortion, the client's response on individual options ranged 0 to $14(0 \%$ to $23.3 \%)$. Regarding unsafe abortion, 14 respondents (23.3\%) answered that a son preference was a leading factor. This was followed by the lack of information about legalization of abortion $13(21.6 \%)$. Results of the posttest, respondents were 29 to 59 (48.3\% to $98.3 \%)$ on individual questions.

The pre-test shows that $23(38.3 \%)$ respondents were aware of the legalization of abortion and the posttest result showed that $60(100 \%)$ gave the correct response. Likewise, the pre-test results for awareness of what the law states when a safe abortion is authorized revealed that the respondents' correct responses ranged from 3 to 13 ( $5 \%$ to $21.6 \%$ ). This showed that most of the respondents did not know about the existing law regarding abortion. Similarly, with regard to restrictions for abortion, $10(16.6 \%)$ respondents answered about the restriction of sex selection. Other individual points had a low number response of respondents. The respondents' post-test results ranged from 36 to 60 $(50 \%$ to $100 \%)$ on the indication and restriction for abortion.

Respondents' awareness in summarized form in pretest and post-test results. The paired t- test was applied at a 0.05 level of significance for testing the hypothesis to determine the difference in total awareness on safe abortion among reproductive age women (2035 years). It includes the meaning of abortion, unsafe and safe abortion, causes and consequences of unsafe abortion, preventive measures as well as safe abortion types, personnel and institutions for safe abortion services and legalization conditions for indications and restrictions for abortion with total score 52 . The final pre-test and post-test mean score with standard deviation was $11.18 \pm 12.88$ and $75.28 \pm 9.56$. The mean difference was 64.1 . The results reveal that there is a statistical significant difference in pre-test and posttest awareness following an educational intervention. In order to measure the statistical significant difference in mean, a standard deviation of total scores between pre-test and post-test awareness results was calculated and the hypothesis was accepted that a significant increase in the level of awareness on the safe abortion among reproductive age women will occur after an educational intervention. The research hypothesis was also accepted at $p$ value paired t-test is $<0.001$ (0.05). It can be concluded through these study results that the educational intervention was effective in increasing the awareness of safe abortion among women of reproductive age.

\section{DISCUSSION}

The result of rural reproductive age group women selected for this study indicates that they are more likely landing to an unsafe abortion compared to urban women. The socio-demographic findings of this study revealed that among 60 respondents, most of them $(43.3 \%)$ were in the age group of 31-35 years. According to their religion the majority $(88.3 \%)$ of women were Hindu. Also, most of the respondents (55\%) were of the Chhetri ethnic group, and $65 \%$ belonged to a nuclear family. Another comparative study might be worthwhile to verify whether there is variation in knowledge on safe abortion among reproductive aged women based on their religious belief and ethnicity.

The pre-test result revealed that only $5 \%$ of the respondents knew the meaning of abortion, whereas in the post-test (after the educational intervention) revealed their response increased to $93 \%$. On the subject of the meaning of unsafe abortion, $18.3 \%$ of 
the respondents answered termination by unhygienic objects, followed by $15 \%$ for untrained health workers. In the post-test after the educational intervention these respondents increased in the range of (27 to 57 ) $45 \%$ to $95 \%$. The findings from this study are supported by a study conducted by Webb, D. on Attitudes to 'Kaponya Mafumo: the terminator of pregnancy in Urban Zambia. ${ }^{5}$

On the topic of the meaning of safe abortion, 5 to 10 respondents $(8.3 \%$ to $16.6 \%)$ had knowledge in the pre-test which increased $53(88.3 \%)$ in the post-test. Earlier study by Tuladhar and Risal reported that a large proportion $(71 \%)$ of the women were unaware of the comprehensive abortion services made available in hospital. ${ }^{6}$

Regarding the reasons for seeking abortion, 21 respondents $(35 \%)$ answered in the pre-test that after completion of family as the main reason for seeking abortion. The finding supports the earlier finding of research conducted by in Thapa, Malla and Basnet. They reported that nearly three persons out of five $160 \%)$ gave the reason for termination as already having the number of children desired. ${ }^{7}$

The next were multiple response questions about the leading factors of unsafe abortion. About 23 respondent in the pre-test answered that not having a son (male preference) was the main reason for seeking an unsafe abortion. It could be due to lack of clear information about what is legal and what is illegal. The post-test results significantly increased that ranged from $98.3 \%$ to $96.6 \%$. Most of the respondents were aware of the ban on sex-selective abortion and despite the overall positive views of legalized abortion; they perceived sex selection as an increasing problem. Greater availability of abortion and ultrasound sonography, along with the high value placed on having male children, were seen as contributing factors for illegal sex selective procedures in a study conducted by Lamichhane et al. ${ }^{8}$

On the topic of the immediate consequences of unsafe abortion, the pre-test response ranged from 2 to $24(3.3 \%$ to $40 \%)$, whereas in the post-test 60 respondents $(100 \%)$ answered correctly. Regarding excessive bleeding, only $19(31.6 \%)$ respondents in the pre-test answered correctly. The pre-test and post-test awareness mean difference was significantly high, which showed that reproductive age women are still unaware about consequences of unsafe abortion. Most common complication from unsafe abortions is excessive blood loss and infection resulting in septic shock. This finding is supported by the study result of Singh. ${ }^{9}$

Pre-test on promotion of awareness to the society about safe abortion ranged from 1 to $22(1.6 \%$ to $36.6 \%)$, whereas the response results were 4 to 58 $(6.6 \%$ to $96.6 \%)$ in the post- test. The mean score with standard deviation was $0.33 \pm 0.60$ in the pre-test and $2.30 \pm 0.69$ in the post-test. The research supports earlier publications by the Ministry of Health, (2005), that advocacy and public awareness campaigns are needed to create awareness of the new legislation, modify social attitudes towards abortion, inform women and their families about the availability of safe abortion services and create an enabling environment for them to make informed decisions. ${ }^{2}$

In regard to the awareness of safe abortion among respondents, only $2(3.3 \%)$ of them were aware of the methods of safe abortion services and $4(6.7 \%)$ were aware of using service provider personnel for safe abortion services in the pre-test. In the post-test, all 60 respondents $(100 \%)$ correctly answered the methods of safe abortion services. Likewise, 12 respondents answered in the pre-test that institutions provide safe abortion services, whereas in the post-test 56 193.3\% ) of the respondents answered each option correctly. In the pre-test only 24 (39.9\%) respondents were aware that government health post and government hospitals are providing safe abortion services. This study showed that rural women are not aware of the services provided by government facilities. Although Nepal has legalized abortion since 2002 , only $38.3 \%$ respondents were found to be aware about the legalization of abortion in the pre-test. In the post-test all 60 (100\%) of respondents were aware of this information. These findings are supported by previous study conducted by the MOHP in 2006 and CREHPA.

Regarding the indications of safe abortion, just up to 13 respondents answered correctly in the pre-test about the different options and in the post-test that was significantly higherdue to educational intervention.. This finding is supports previous study conducted by the MOHP in 2009. ${ }^{10}$

Regarding restriction of abortion, in the pre-test $16.6 \%$ of the respondents gave the answer as sex selection and in the post-test all of respondents (100\%) answered correctly. This finding supported by a study conducted by Lamichhane et al. ${ }^{8}$ 
Table 1. Respondents' Demographic Characteristics $(n=60)$.

\begin{tabular}{|c|c|c|}
\hline Demographic Factors & $\mathbf{n}$ & $\%$ \\
\hline \multicolumn{3}{|l|}{ Age Group(Yrs) } \\
\hline $20-25$ & 23 & 38.3 \\
\hline $25-30$ & 11 & 18.3 \\
\hline $30-35$ & 26 & 43.3 \\
\hline Mean \pm SD & $28.82 \pm 4.97$ & \\
\hline \multicolumn{3}{|l|}{ Religion } \\
\hline Hindu & 53 & 88.3 \\
\hline Buddhist & 5 & 8.3 \\
\hline Christian & 2 & 3.3 \\
\hline \multicolumn{3}{|l|}{ Ethnic Group } \\
\hline Brahmin & 15 & 25 \\
\hline Chhetri & 33 & 55 \\
\hline Others & 12 & 20 \\
\hline \multicolumn{3}{|l|}{ Education of Respondents } \\
\hline Illiterate & 3 & 5.0 \\
\hline Below SLC & 39 & 65.0 \\
\hline SLC and above SLC & 18 & 30.0 \\
\hline \multicolumn{3}{|l|}{ Occupation of Respondents } \\
\hline Agriculture and Household & 47 & 78.3 \\
\hline Student & 5 & 8.3 \\
\hline Service & 6 & 10.0 \\
\hline Business & 2 & 3.3 \\
\hline
\end{tabular}

Table 2. Pre-Test and Post-Test Awareness of Respondents on Meaning of Abortion, Unsafe Abortion And Safe Abortion $(n=60)$.

$\begin{array}{rrrrr}\text { Variables } & \text { Pre-test } & & \text { Post- test } \\ & n & (\%) & n & (\%)\end{array}$

Meaning of Abortion*

Termination of pregnancy before the fetus is

$3 \quad 15.0 \quad 56$

viable (before 4-5 months)

Meaning of Unsafe Abortion*

Termination by untrained Health worker 9

$9 \quad$ (15.0) 57

Termination by domestic Herbs and medicine 1

Termination by unhygienic objects

40

Termination by blunt injury

52

Listed criteria for Safe Abortion*

Service provided by trained Health Personnel 10

$10 \quad(16.6) \quad 51$

(85.0)

Service provided by trained Health Personnel in certified Institutions 5

53

Under consent of pregnant women on legal framework

(8.3)

34

(56.7)

Mean score awareness \pm SD

$0.75 \pm 1.06$

$6.15 \pm 1.35$

$P$ value

* Multiple responses 
Table 3. Respondents' Awareness about Reasons for Seeking Abortion and Leading Factors to Unsafe Abortion Before and After Educational Intervention $(n=60)$.

\section{Variable}

Reasons for seeking abortion*

After sex selection

After completion of Family

For child spacing

Failure of contraception

Wishing to continue with their education

After Incest or rape

Leading factors for Unsafe abortion*

Son preferences

Lack of confidentiality/privacy

Fear of criticism by their society related to cultural norms and beliefs.

Not affordable

Lacking of information about legalization

Mean score awareness \pm SD

$P$ value
Pre- test

n

5

21

2

3

2

15

14

$-$

\section{2}

4

13

$1.31 \pm 1.59$
Post- test

n

(\%)

(\%)

(8.3)

59

(98.3)

(35.0)

56

(93.3)

(81.6)

(3.3)

(73.3)

(5.0)

49

(3.3)

44

(66.6)

(25.0)

(98.3)

59

(23.3)

59

(98.3)

- 42

(70.0)

(3.3) 47

(78.3)

(6.6)

29

(48.3)

(21.6)

58

(96.6)

*Multiple responses

Table 4. Respondents' Awareness about Abortion Law of Nepal $(n=60)$.

\begin{tabular}{|c|c|c|c|c|}
\hline \multirow{2}{*}{ Variable } & \multicolumn{2}{|c|}{ Pre-test } & \multicolumn{2}{|c|}{ Post-test } \\
\hline & $\mathbf{n}$ & $(\%)$ & $\mathbf{n}$ & $(\%)$ \\
\hline \multicolumn{5}{|l|}{ Legalization abortion } \\
\hline Don't know & 37 & $(61.6)$ & - & - \\
\hline Know (Yes) & 23 & (38.3) & 60 & $(100)$ \\
\hline \multicolumn{5}{|l|}{ Indication for Safe abortion* } \\
\hline Any pregnancy up to 12 weeks & 3 & $(5.0)$ & 58 & (96.6) \\
\hline Incest or rape cases up to 18 weeks of gestation & 13 & $(21.6)$ & 58 & (96.6) \\
\hline Abnormal fetus for any age of gestational weeks & 5 & (8.3) & 45 & $(75.0)$ \\
\hline Risk to mother for any age of gestational weeks & 8 & (13.3) & 51 & $(85.0)$ \\
\hline Above 16 years and under consent of her & - & - & 24 & $(40.0)$ \\
\hline \multicolumn{5}{|l|}{ Restricted condition for abortion* } \\
\hline Sex selective & 10 & $(16.6)$ & 60 & $(100)$ \\
\hline Without consent of the pregnant woman & 5 & (8.3) & 54 & (90.0) \\
\hline Below 16 years and without guardian's consent & - & - & 36 & $(50.0)$ \\
\hline Beyond the gestational age mentioned by Law & 5 & $(8.3)$ & 52 & $(86.6)$ \\
\hline Mean awareness score \pm SD & \multicolumn{2}{|c|}{$1.23 \pm 1.25$} & \multicolumn{2}{|c|}{$8.30 \pm 1.2$} \\
\hline$P$ value & \multicolumn{4}{|c|}{$<0.001$} \\
\hline
\end{tabular}

*Multiple responses 
Table 5. Comparison Between Pre-Test And Post- Test Awareness Regarding Abortion, Unsafe Abortion And Safe Abortion $(n=60)$.

\begin{tabular}{|c|c|c|c|c|}
\hline Variable & $\begin{array}{l}\text { Item wise } \\
\text { total Score }\end{array}$ & $\begin{array}{c}\text { Pre-test } \\
\text { Mean } \pm \text { SD }\end{array}$ & $\begin{array}{l}\text { Post-test } \\
\text { Mean } \pm \text { SD }\end{array}$ & $\begin{array}{l}\text { Mean } \\
\text { Differences }\end{array}$ \\
\hline $\begin{array}{l}\text { 1. Meaning of abortion, Unsafe abortion and Safe } \\
\text { abortion }\end{array}$ & 9 & $0.75 \pm 1.06$ & $6.15 \pm 1.35$ & 5.4 \\
\hline $\begin{array}{l}\text { 2. Reasons and leading factors of abortion and } \\
\text { unsafe abortion }\end{array}$ & 11 & $1.31 \pm 1.59$ & $9.01 \pm 1.57$ & 7.7 \\
\hline 3. Consequences of Unsafe abortion & 11 & $1.23 \pm 1.54$ & $7.48 \pm 1.25$ & 6.2 \\
\hline 4. Promotive measures of safe abortion & 5 & $0.33 \pm 0.66$ & $2.30 \pm 0.69$ & 1.97 \\
\hline $\begin{array}{l}\text { 5. Safe abortion- methods, Service provider } \\
\text { (Personnel) and service Provider Institutions }\end{array}$ & 6 & $0.66 \pm 0.95$ & $4.8 \pm 0.49$ & 4.14 \\
\hline 6. Legalization of abortion & 10 & $1.23 \pm 1.55$ & $8.30 \pm 1.22$ & 7.07 \\
\hline Total Pre-test and Post-test Mean Score \pm SD & 11.18 & \pm 12.88 & 75.28 & 9.56 \\
\hline Total Mean Differences & \multicolumn{4}{|c|}{64.1} \\
\hline p- value & \multicolumn{4}{|c|}{$<0.001$} \\
\hline
\end{tabular}

Shortage of adequately trained trainers in health education resources

\section{CONCLUSIONS}

This study has shown that reproductive age women in the rural community have a low level of awareness regarding

safe abortion services, promotion measures and legalization of abortion. The study has also shown that awareness levels of reproductive age women in rural areas can be significantly increased through the use of an educational interventions that promotes the use of safe abortion services facilitated by the government. Safe abortion services awareness can be imparted among the reproductive age women to prevent morbidity and mortality of women.

\section{ACKNOWLEDGEMENT}

Authors acknowledge the contribution made by Dr. Sarala Shrestha during the study design and data interpretation.

\section{REFERENCES}

1. Nepal Demographic and Health Survey 2011, Population Division, Ministry of Health and Population, Kathmandu, Nepal, August 2011

2. Ministry of Population and Environment, Nepal Population Report, Kathmandu; 2005.

3. Kieran Walshe and Judith Smith (eds), Healrthcare management, Open University Press, McGraw-Hill Education, McGraw-Hill House, London, England, 2006, p.94

4. Overview of Public-Private Mix in Health Care Service Delivery in Nepal, Ministry of Health and Population Government of Nepal, June 2010 p.9

5. Webb D, Atitudes to 'Kaponya Mafumo: the terminator of pregnancy in Urban Zambia. Health policy plan.115 (2), 2000.
6. Tuladhar $\mathrm{H}$, Risal A. Level of awareness about legalization of abortion in Nepal: A study at Nepal Medical college teaching Hospital, Kathmandu, Nepal, 2010.

7. Thapa S, Malla K, Basnet I. World Health population: Safe abortion in Nepal. J Nepal Health Res Counc. 2010; 11(3):55-68.

8. Lamichhane P, Harken T, Puri M, Darney PD, Blum M, Harper CC, Henderson J T. Sex selective abortion in Nepal: a qualitative study of Health workers perspectives, 2011.

9. Singh S. Global consequences of unsafe abortion. Womens Health (Lond Engl). 2010 Nov;6(6):849-60.

10. Ministry of Health. Family Health division. The women's Right to choose: Partnership for safe abortion in Nepal. Technical committee for the implementation of comprehensive Abortion Care. 2005. 